\title{
O RECONHECIMENTO DAS DECISÕES DOS TRIBUNAIS DE CONTAS EM AÇÕES DE RESPONSABILIZAÇÃO
}

\author{
Rodrigo Ematné Gadben* \\ Paulo Roberto Miguez Bastos da Silva**
}

\begin{abstract}
Resumo
O presente artigo apresenta uma análise sobre os Tribunais de Contas e suas decisões, bem como sua revisibilidade pelo Poder Judiciário, tratando tais decisões à luz da Teoria dos Poderes Neutrais e dos efeitos sistêmicos imprevisíveis para, após isso, apresentar a argumentação dos autores da necessidade dessas decisões dos tribunais de Contas integrarem as ações judiciais que tratam de questões relativas a suas competências, em especial a Ação Civil de Improbidade Administrativa.
\end{abstract}

Palavras-chave: Tribunal de Contas, Poderes Neutrais, Poder Judiciário, Ações Judiciais, Improbidade.

\begin{abstract}
This article presents an analysis of the Audit Courts and their decisions, as well as their revisability by the Judiciary, dealing with such decisions in the light of the Theory of Neutral Powers and the unpredictable systemic effects to, after that, present the arguments of the authors of the need of these decisions of the Audit Courts integrate the legal actions that deal with issues related to their competences, in particular the Civil Action for Administrative Improbity.
\end{abstract}

Keywords: Audit Courts, Neutral Powers, Judiciary, Lawsuits, Improbity.

\section{Introdução}

Certa vez, ao analisarmos uma Ação Civil Pública que versava sobre a execução de despesa de um contrato administrativo, fomos tomados de uma inquietação: como era possível que o órgão responsável pelo controle externo da execução de despesas dos contratos administrativos oriundos da Lei $n^{0} 8.666 / 93^{1}$, não fosse parte da ação ou sequer era chamado

\footnotetext{
* Mestrando em Direito da Regulação pela FGV Direito Rio. Especialista em Direito Empresarial pela FGV Rio e em Direito Público pela Universidade Anhanguera UNIDERP/LFG. Advogado. E-mail: gadben @ hotmail.com

** Mestrando em Direito da Regulação pela FGV Direito Rio e Pós-graduado em Regulação e Direito do Estado (FGVRJ). Advogado. E-mail: pmiguez@uol.com.br

${ }^{1}$ A questão surgiu em decorrência do art. 113, caput da Lei $\mathrm{n}^{0} \quad$ 8.666/93, que encontra similitude com o art. 169, III da Lei $n^{0}$ 14.133/2021:

"Art. 113. O controle das despesas decorrentes dos contratos e demais instrumentos regidos por esta Lei será feito pelo Tribunal de Contas competente, na forma da legislação pertinente, ficando os órgãos interessados da
} 
a se manifestar nela? Afinal, o Tribunal de Contas, que é a entidade constitucional competente e, portanto, especializada para realizar o escrutínio desse ato, não integrava a mencionada ação judicial.

Em nosso dia a dia, nos deparamos com inúmeras Ações Civis Públicas de Improbidade Administrativa que versam sobre dano ao erário, execução de despesas oriundas de contratos administrativos, Termos Aditivos de valores ou mesmo reequilíbrio econômicofinanceiro desses contratos administrativos sem a participação do órgão responsável pelo controle externo da Administração. Tal situação nos inspirou a trazer esse debate à luz, objetivando a melhoria de nosso sistema de controle como um todo.

As questões envolvendo as competências dos Tribunais de Contas não são novas na doutrina pátria. Sobretudo no que se refere ao Tribunal de Contas da União ${ }^{2}$, não são poucos os artigos que focam suas análises nas competências da Corte, além de seus limites e eventuais extrapolações.

A Carta de 1988 criou um sistema de controle da Administração Pública com inúmeras instituições e ferramentas que exercem esse controle, tanto interno quanto externo, visando dar maior proteção do cidadão em face do Estado e garantia da qualidade da gestão pública. Em outras palavras, durante o período da Assembleia Nacional Constituinte - ANC, os mecanismos de controle vivenciaram uma significativa expansão, não apenas na proteção do cidadão em face do Estado, mas também na dimensão gerencial, afeita a qualidade da gestão pública (PEREIRA, 2019).

\footnotetext{
Administração responsáveis pela demonstração da legalidade e regularidade da despesa e execução, nos termos da Constituição e sem prejuízo do sistema de controle interno nela previsto."

"Art. 169. As contratações públicas deverão submeter-se a práticas contínuas e permanentes de gestão de riscos e de controle preventivo, inclusive mediante adoção de recursos de tecnologia da informação, e, além de estar subordinadas ao controle social, sujeitar-se-ão às seguintes linhas de defesa:

I - primeira linha de defesa, integrada por servidores e empregados públicos, agentes de licitação e autoridades que atuam na estrutura de governança do órgão ou entidade;

II - segunda linha de defesa, integrada pelas unidades de assessoramento jurídico e de controle interno do próprio órgão ou entidade;

III - terceira linha de defesa, integrada pelo órgão central de controle interno da Administração e pelo tribunal de contas.

..”

${ }^{2}$ Com base no Art. 75 da Constituição Federal aplicam-se, no que couber, aos Tribunais de Contas estaduais e municipais às normas de organização, composição e fiscalização estabelecidas para o Tribunal de Contas da União. Portanto, pode-se dizer que as colocações sobre o TCU, de maneira geral, aplicam-se aos demais TCs.
} 
O Tribunal de Contas da União, com suas competências ${ }^{3}$, foi previsto na Carta de 1988 como um órgão integrante de um sistema de controle mais amplo, que tem por objetivo uma atuação em duas dimensões, uma que busca uma maior qualidade na gestão pública e outra que busca proteger o cidadão de abusos eventualmente praticados pelo Estado.

É importante o fato de que, se fosse desejo do constituinte originário, o TCU e as demais Cortes de Contas poderiam ter sido amplamente remodelados, especialmente porque estávamos construindo uma nova Carta Magna, permitindo-se a definição de competências diferentes e a delimitação da intensidade do controle a ser exercido. Entretanto, isso não foi o que ocorreu, talvez por ser o TCU uma das instituições mais antigas do Brasil, datando sua

\footnotetext{
${ }^{3}$ A competência do Tribunal de Contas da União é prevista no art. 71 da Constituição Federal:

“Art. 71. O controle externo, a cargo do Congresso Nacional, será exercido com o auxílio do Tribunal de Contas da União, ao qual compete:

I - apreciar as contas prestadas anualmente pelo Presidente da República, mediante parecer prévio que deverá ser elaborado em sessenta dias a contar de seu recebimento;

II - julgar as contas dos administradores e demais responsáveis por dinheiros, bens e valores públicos da administração direta e indireta, incluídas as fundações e sociedades instituídas e mantidas pelo Poder Público federal, e as contas daqueles que derem causa a perda, extravio ou outra irregularidade de que resulte prejuízo ao erário público;

III - apreciar, para fins de registro, a legalidade dos atos de admissão de pessoal, a qualquer título, na administração direta e indireta, incluídas as fundações instituídas e mantidas pelo Poder Público, excetuadas as nomeações para cargo de provimento em comissão, bem como a das concessões de aposentadorias, reformas e pensões, ressalvadas as melhorias posteriores que não alterem o fundamento legal do ato concessório;

IV - realizar, por iniciativa própria, da Câmara dos Deputados, do Senado Federal, de Comissão técnica ou de inquérito, inspeções e auditorias de natureza contábil, financeira, orçamentária, operacional e patrimonial, nas unidades administrativas dos Poderes Legislativo, Executivo e Judiciário, e demais entidades referidas no inciso II;

V - fiscalizar as contas nacionais das empresas supranacionais de cujo capital social a União participe, de forma direta ou indireta, nos termos do tratado constitutivo;

VI - fiscalizar a aplicação de quaisquer recursos repassados pela União mediante convênio, acordo, ajuste ou outros instrumentos congêneres, a Estado, ao Distrito Federal ou a Município;

VII - prestar as informações solicitadas pelo Congresso Nacional, por qualquer de suas Casas, ou por qualquer das respectivas Comissões, sobre a fiscalização contábil, financeira, orçamentária, operacional e patrimonial e sobre resultados de auditorias e inspeções realizadas;

VIII - aplicar aos responsáveis, em caso de ilegalidade de despesa ou irregularidade de contas, as sanções previstas em lei, que estabelecerá, entre outras cominações, multa proporcional ao dano causado ao erário;

IX - assinar prazo para que o órgão ou entidade adote as providências necessárias ao exato cumprimento da lei, se verificada ilegalidade;

$\mathrm{X}$ - sustar, se não atendido, a execução do ato impugnado, comunicando a decisão à Câmara dos Deputados e ao Senado Federal;

XI - representar ao Poder competente sobre irregularidades ou abusos apurados.

$\S 1^{\circ}$ No caso de contrato, o ato de sustação será adotado diretamente pelo Congresso Nacional, que solicitará, de imediato, ao Poder Executivo as medidas cabíveis.

$\S 2^{\circ}$ Se o Congresso Nacional ou o Poder Executivo, no prazo de noventa dias, não efetivar as medidas previstas no parágrafo anterior, o Tribunal decidirá a respeito.

$\S 3^{\circ}$ As decisões do Tribunal de que resulte imputação de débito ou multa terão eficácia de título executivo. $\S 4^{\circ} \mathrm{O}$ Tribunal encaminhará ao Congresso Nacional, trimestral e anualmente, relatório de suas atividades."
} 
criação de 1890, fazendo com que o modelo até então adotado estivesse bastante consolidado (ROSILHO, 2016).

Apesar da remodelação das Cortes de Contas não ter ocorrido, algumas mudanças e novidades foram trazidas pela Carta de 1988, como é o caso do Controle Operacional, conforme apontado por Floriano de Azevedo Marques Neto e Juliana Bonacorsi de Palma (2020, p. 212), que escreveram: "conscientemente, ou não, a Assembleia Nacional Constituinte imprimiu um novo projeto ao Tribunal de Contas: o exercício da fiscalização operacional."

Dessa forma, o modelo de tribunal de contas que já existia foi mantido com algumas ampliações que iam além da fiscalização contábil, financeira e orçamentária, ou seja, rompeuse com a tradição da fiscalização tríplice, objetivando uma maior efetividade das Cortes de Contas dentro do sistema de controle idealizado (MARQUES NETO; PALMA, 2020), o que também foi observado por André Rosilho (2016, p. 76), que apontou que a “impressão que se tem é a de que o processo de reforma das competências dos tribunais de contas foi incremental [...]", sendo que o grifo foi feito pelo autor.

Ë importante salientar que desde a promulgação da Constituição Federal de 1988, o controle da Administração Pública vem experimentando um constante aumento, motivado pelo desejo de que, não só essa Administração seja proba, mas que ela não seja abusiva com relação aos administrados. Pode-se dizer que esse desejo veio na esteira do momento histórico que vivíamos, pois deixávamos para trás um Estado que tudo podia em detrimento de seus cidadãos, pretendendo construir um novo Estado que protegesse e cuidasse desses cidadãos ao invés de subjugá-los.

Esse aumento do controle da Administração Pública não trouxe apenas benefícios, mas também alguns problemas, como por exemplo a falta de coordenação entre os vários órgãos de controle ou a sobreposição deles, que fiscalizam a mesma conduta do agente público de forma justaposta, perdendo tempo e tornando o custo do controle elevado e insegurança jurídica ao administrador público.

Em 2017, em artigo intitulado "Os Sete impasses do Controle da Administração Pública no Brasil”, Floriano de Azevedo Marques Neto e Juliana Bonacorsi de Palma (2017) identificaram, com rara precisão, os principais problemas que envolvem o controle da Administração Pública no Brasil. Segundo os autores, esses problemas poderiam ser resumidos nos seguintes impasses: 
(i) Captura das competências públicas: as competências administrativas deslocamse para órgãos e entes com maior prestígio (não raro sem capacidade institucional para lidar com a gestão pública)

(ii) Neopatrimonialismo: o controle é orientado pelas predileções pessoais e orientação jurídica do funcionário controlador

(iii) Desvirtuamento da atividade-fim: os gestores públicos priorizam mais atender às demandas dos controladores do que cumprir com as atividades-fim da Administração Pública

(iv) Reais efeitos do combate à corrupção: a cultura do controle é realmente eficaz no combate à corrupção?

(v) Gestão de defesa: o administrador de boa-fé é refém do controle

(vi) Competição institucional: os órgãos de controle competem entre si

(vii) Decisões instáveis: a estrutura do sistema de controle desfavorece decisões definitivas

Em linhas gerais, os artigos que tratam dos Tribunais de contas, especialmente o Tribunal de Contas da União, focam especialmente nos impasses referentes a captura das competências públicas, ao desvirtuamento da atividade-fim e a gestão de defesa. Nesse sentido, a doutrina vem analisando as eventuais extrapolações de competência praticadas pelo Tribunal de Contas da União, bem como vem estudando a natureza e validade das decisões das Cortes de Conta.

Entretanto, como diziam nossos avós, "quem procura serviço é porque está com o seu pronto ou mal feito". Apesar de ser um adágio é interessante e deve ser colocado em perspectiva, já que não acreditamos que os Tribunais de Contas esgotem todo o trabalho decorrente de suas competências, nem que eles executem esse trabalho sem a qualidade necessária. O que entendemos estar acontecendo é que a atuação de outros órgãos integrantes do sistema de controle vem se sobrepondo a atuação dos Tribunais de Contas, fazendo com que eles busquem novas competências objetivando a manutenção de sua relevância, que entendem estar perdendo.

Não queremos aqui discutir se as decisões dos Tribunais de Contas podem ou não serem revistas pelo Poder Judiciário, nos alinhamos a corrente doutrinária que entendi que sim e em qualquer caso. Nossa proposta é um pouco diferente, pretendendo analisar o controle dos Tribunais de Contas dentro da esfera da competição institucional e das decisões instáveis, mas de maneira inversa, ou seja, em que medida outros órgãos do sistema de controle vêm se sobrepondo às competências dos Tribunais de Contas, fazendo com que eles sejam alijados de processos dos quais deveriam participar e se isso cria algum tipo de instabilidade na definitividade das decisões. Essa, por sua vez, tem como consequência a insegurança jurídica do administrador que, embora tenha suas contas fiscalizadas e declaradas 
regulares pelo tribunal de contas competente, pode ser surpreendido pela ação de outro controlador.

O presente artigo tem objetivo essencialmente descritivo e opinativo, objetivando discorrer sobre os Tribunais de Contas e a natureza de suas decisões e sua revisibilidade pelo Poder Judiciário para então apresentarmos nossa argumentação sobre como os Tribunais de Contas devem integrar as ações judiciais que envolvem suas competências, especialmente as Ações Civis Públicas de Improbidade Administrativa.

\section{Natureza dos Tribunais de Contas e de suas Decisões}

A leitura da Seção IX do Título - Da Fiscalização Contábil, Financeira e Orçamentária Constituição da República Federativa do Brasil de 1988 - CRFB/88 pode induzir ao leitor mais apressado que o Tribunal de Contas da União seria um órgão vinculado ao Poder Legislativo, tendo em vista na dicção literal do Art. 71, que atribui a esse órgão o caráter de auxiliar no controle externo da fiscalização contábil, financeira e orçamentária ${ }^{4}$. Porém, trata-se de órgão independente responsável pela apreciação das contas do chefe do Poder Executivo Federal, julgar as contas dos administradores e demais dinheiros, bens e valores públicos da administração direta e indireta, incluídas as fundações e as sociedades instituídas e mantidas pelo Poder Público federal, bem como as contas daqueles que derem causa a perda, extravio ou outra irregularidade de que resulte prejuízo ao erário federal, entre outras. 5

Letícia Ayres Ramos, em sua dissertação de mestrado, fazendo referência a passagem do livro de Castro Nunes (apud RAMOS, p. 17, nota de rodapé 13), nos informa que o "[t]ribunal de contas é um instituto sui generis, posto de permeio entre os Poderes políticos da nação, Legislativo e o Executivo, sem sujeição, porém, a qualquer um deles.”

Da análise do Art. 44 da CRFB/88 depreende-se que o TCU não integra o Poder Legislativo. Conforme se infere do texto de Letícia Ayres Ramos, nas palavras de Odete

\footnotetext{
${ }^{4}$ Art. 71. O controle externo, a cargo do Congresso Nacional, será exercido com o auxílio do Tribunal de Contas da União, ao qual compete: (grifamos)

${ }^{5}$ Para uma leitura completa das competências do TCU, sugere-se a leitura do Art. 71 da CRFB/88 (nota de rodapé 6). Adicionalmente trazemos a colação, que de acordo com o Art. 75 desse mesmo diploma, as normas estabelecidas nessa seção se aplicam aos Tribunais de Contas Estaduais e Municipais, no que couber.
} 
Medaur, não existe hipótese de se considerar o aquele órgão como órgão atrelado aquele poder (RAMOS, op. cit.).

A Teoria do Poderes Neutrais, em sua elaboração mais recente, torna mais clara a posição institucional dos Tribunais de Contas e suas decisões, bem como nos ajuda a entender melhor sua natureza como órgão independente de controle (ARAGÃO, 2003).

Segundo a citada teoria, os diversos órgãos que compõem os Poderes Neutrais do Estado possuem um grau de autonomia variável, mas compartilham certas características. Tais características, de acordo com Alexandre Santos de Aragão (2003) são: (i) o provimento de seus titulares é feito de forma não eletiva; (ii) os órgãos possuem natureza e funções dominantemente técnicas; (iii) devem possuir independência dos poderes tradicionais, caracterizada pela ausência de subordinação; e (iv) devem exercer sus funções de forma imparcial.

No mesmo sentido, Mariana Montebello Willeman (2016), associando os Tribunais de Contas aos poderes neutrais, ainda estabelece as principais características que se sobressaem em instituições dotadas dessas funções neutrais da seguinte forma:

... [E]m primeiro lugar, destaca-se que a legitimidade de sua autoridade repousa sobre duas exigências que se entrelaçam, quais sejam, a qualificação técnica (expertise) e a imparcialidade, esta última compreendida no sentido de descompromisso partidário e neutralidade em relação aos diversos interesses que podem estar em jogo na sua esfera de atuação. Diretamente associado a esse ponto, há o caráter não eletivo do provimento de seus titulares, os quais ficam, ao menos teoricamente, afastados da dinâmica político-partidária. E há, por fím, o reconhecimento da independência necessária para assegurar a emancipação política da instituição. (WILLWMAN, 2016, p. 193)

O STF também reconhece os Tribunais de Contas como "órgão centralmente constitucionais independentes e autônomos" (WILLWMAN, op. cit., p. 198), o que se conforma com a ordem constitucional e com a Teoria dos Poderes Neutrais, especialmente porque a Constituição de 1988 também reservou garantias institucionais e subjetivas aos integrantes das Cortes de Contas da mesma forma que o fez para os integrantes do Poder Judiciário, demonstrando a intenção do constituinte de que essas Corte de Contas tivessem as características necessárias para uma atuação imparcial.

Em que pese o órgão tenha na terminologia o vocábulo Tribunal, este não compõe os órgãos do Poder Judiciário previstos no Art. 92 da CRFB/ $88^{6}$. Outro aspecto que ressalta a

\footnotetext{
${ }^{6}$ Art. 92. São órgãos do Poder Judiciário: (EC no 45/2004)
} 
impropriedade da nomenclatura, segundo Cretella Jr. (1986), se é Tribunal, pressupõe-se que haja um primeiro grau. E ele existe?

Ainda segundo esse autor, a fiscalização não é função jurisdicional. Não há contencioso administrativo que faça coisa julgada insulada ao Poder Judiciário. O Direito Pátrio não adota a jurisdição administrativo, como é o caso de alguns países, como a França, que possui o Conselho de Estado.

Com base em suas atribuições constitucionais o TCU se enquadra nas instituições superiores de auditoria externa (Supreme Audit Institutions), segundo a International Organization of Supreme Audit Institutions (INTOSAI), organização internacional com status consultivo no Conselho Econômico e Social das Nações Unidas (SUNDFELD et al., 2017).

As decisões do TCU e dos demais tribunais de contas têm natureza administrativa sem qualquer característica e força de decisão judicial. Na visão de Sundfeld et al (2017, p. 8), o TCU é órgão de controle externo especial "não é órgão judicial, tampouco produz decisões judiciais". Nessa linha de pensamento, que não atribuem caráter jurisdicional as decisões dos tribunais de contas, destacam-se José Afonso da Silva, Hely Lopes Meirelles, Cretella Júnior, Lucia Vale Figueiredo e Oswaldo Aranha (RAMOS, Op. Cit., p. 30) ${ }^{7}$.

Entretanto, essa posição não é uníssona na doutrina, há quem defenda que os tribunais de contas exercem função jurisdicional. Pontes de Miranda entendia que, formalmente, o tribunal de contas seria um órgão auxiliar do Poder Legislativo, porém, em termos materiais exerceria função judicante. Engrossam essa fileira, entre outros, Seabra Fagundes, Rodolfo Camargo Mancuso e Jorge Jacoby Fernandes (RAMOS, Op. Cit., p. 28).

$\mathrm{Na}$ verdade, podemos dizer que os Tribunais de Contas, mesmo que não exerçam a função jurisdicional, possuem um certo caráter jurisdicional, visto que suas decisões não são puramente administrativas e possuem fundamento constitucional. Além disso, suas decisões se sobrepõem às dos órgãos que são controlados por ele, não importando em que nível

I - o Supremo Tribunal Federal;

I-A - o Conselho Nacional de Justiça;

II - o Superior Tribunal de Justiça;

III - os Tribunais Regionais Federais e Juízes Federais;

IV - os Tribunais e Juízes do Trabalho;

V - os Tribunais e Juízes Eleitorais;

VI - os Tribunais e Juízes Militares;

VII - os Tribunais e Juízes dos Estados e do Distrito Federal e Territórios.

7 Nesse sentido, recomenda-se a leitura do artigo de autoria de Maria Sylvia Di Pietro Coisa julgada: aplicabilidade a decisões do Tribunal de Contas da União. Revista do Tribunal de Contas da União, Brasília, v. 27, n. 70, 1996, p.26-27. 
hierárquico, sendo ainda que suas decisões vinculam esses órgãos e acarretam responsabilidade na esfera administrativa ao agente público (DI PIETRO, 1996).

Por sua vez, o Supremo Tribunal Federal - STF reconhece a competência julgadora do Tribunal de Contas da União, diferenciando os comandos dos incisos I e II do Art. 71 da Constituição Federal de 1988. No primeiro trata-se de manifestação prévia do tribunal sem o condão de julgar, pois cabe ao Poder Legislativo essa competência. Por sua vez, ao exercer a função prevista no referido inciso II, o TCU julga, porém, a natureza é administrativa e não judicial (DI PIETRO, op. cit.).

Em outras palavras, nos casos em que o Tribunal de Contas julga, o trânsito em julgado administrativo não faz coisa julgada material, pois suas decisões são sempre passíveis de revisão pelo Poder Judiciário, mas faz coisa julgada formal, uma vez que ocorre a preclusão das vias administrativas para as partes envolvidas (DI PIETRO, op. cit.). Assim, temos que apesar dos Tribunais de Contas serem órgãos autônomos e independentes, suas decisões encontram-se na esfera administrava e, portanto, podem ser amplamente revisadas, mas apenas pelo Judiciário, uma vez que tais decisões, mesmo que administrativas, são superiores aos órgãos fiscalizados, possuindo em alguns casos, natureza sancionatória (DI PIETRO, op. cit.).

De acordo com o entendimento sedimentado pela doutrina, não existe um respeito a algum tipo de reserva de competência para Cortes de Contas, especialmente porque a análise de conformidade legal dos contratos administrativos, bem como a análise de eventuais prejuízos causados à Administração por esses contratos são de competência exclusiva dessas Cortes de Contas, mas apenas na esfera administrativa, podendo o judiciário decidir sobre tais matérias de maneira autônoma (SUNDFELD et al, op. cit.).

Nosso entendimento diverge um pouco do sedimentado, especialmente porque apesar da palavra final ser do judiciário, não é adequado que a jurisdição seja exercida sem que o órgão que detém a competência do controle externo seja participante do processo. E esse entendimento é fincado no argumento da capacidade institucional e no risco dos efeitos sistêmicos, defendidos por Luís Roberto Barroso (apud RAMOS, op. cit., p. 133-134):

Essa primazia não significa, porém, que toda e qualquer matéria deva ser decidida em um tribunal. Para evitar que o Judiciário se transforme em uma indesejável instância hegemônica, a doutrina constitucional tem explorado duas ideias destinadas a limitar a ingerência judicial: a de capacidade institucional e a de efeitos sistêmicos. Capacidade institucional envolve a determinação de qual Poder está mais habilitado a produzir a melhor decisão em determinada matéria. Temas 
envolvendo aspectos técnicos ou científicos de grande complexidade podem não ter no juiz de direito o árbitro mais qualificado, por falta de informação ou de conhecimento específico. Também o risco de efeitos sistêmicos imprevisíveis e indesejáveis podem recomendar uma posição de cautela e de deferência por parte do Judiciário. O juiz, por vocação e treinamento, normalmente estará preparado para realizar a justiça do caso concreto, a microjustiça, sem condições, muitas vezes, de avaliar o impacto de suas decisões sobre um segmento econômico ou sobre a prestação de um serviço público.

A capacidade institucional dos Tribunais de Contas é bem conhecida nas áreas em que eles têm a competência para exercer o controle externo, tendo o órgão sido idealizado para a tarefa pelo constituinte, sua estrutura foi se aperfeiçoando ao longo dos anos. Portanto, em nossa opinião, permitir a existência de um processo totalmente autônomo, ignorando o Tribunal de Contas torna-se improdutivo, na medida em que se ignora o órgão mais bem estruturado a se manifestar sobre as questões referentes a fiscalização da execução de despesas de contratos e questões que envolvam lesão ao erário. Trata-se aqui, igualmente, da aplicação da tese da deferências aos entidades especializadas, neste caso, aos tribunais de contas apenas, e tão somente, no que tange as suas competências constitucionais. Portanto, em sendo o resultado do julgamento legal e razoável, essa decisão deve ser homenageada.

Já no que se refere aos efeitos sistêmicos, a participação do órgão responsável pelo controle externo confere ao processo, e porque não ao controle em si, uma maior segurança jurídica, uma vez que, se o judiciário entender de forma diversa do Tribunal de Contas não teremos duas decisões sobrepostas sobre a mesma questão, mas apenas uma única, conforme veremos mais à frente.

Importante destacar que não estamos propondo que o julgamento pelo Poder Judiciário seja vinculado ao do Tribunal de Contas uma vez que isso atentaria contra sua autonomia e poderia ser considerado inconstitucional perante o preceito constitucional do inciso XXXV Art. $5^{\circ}$ da CF. O que se propõe é que o julgamento seja pautado pelo julgamento do Tribunal de Contas, onde o juiz motivará sua decisão com base nessa decisão quando concordar e, quando não concordar, deverá igualmente motivar adequadamente a decisão, rebatendo os argumentos presentes na decisão do órgão responsável pelo controle externo. Em outras palavras, o que se espera é que o Poder Judiciário faça um exercício de autocontenção em deferência as decisões do Tribunal de Contas, sempre que essa decisão seja razoável e não seja ilegal.

Além do acima exposto, temos que a reputação técnica das Cortes de Contas é considerável, visto que os auditores dos Tribunais de Contas são conhecidos pela capacidade 
técnica com que exercem sua competência, especialmente no que concerne a sua função de auditoria. As Cortes de Contas atingiram um alto grau de excelência, o que torna esse Órgão do sistema de controle uma espécie de "auditor natural". Esse status qualifica essas Cortes a integrarem ações judiciais de diversas formas, inclusive atuando como "perito" do juízo, especialmente porque o exame feito pelo Tribunal de Contas abarca a legalidade, a economicidade e a legitimidade, o que nem sempre é possível ao juízo fazer (JACOBY FERNANDES, 2005).

\section{Os Tribunais de Contas e as Ações Judiciais}

Começaremos a análise sobre a necessidade ou não de os Tribunais de Contas integrarem ações judiciais, especialmente as de improbidade administrativa, que versem sobre questões envolvendo suas competências pela constatação de que hoje o entendimento é de que essa participação não é necessária. Entendemos de forma diferente, conforme iremos expor a seguir.

A Lei de Improbidade Administrativa ${ }^{8}$ estabelece, em seu artigo 21, que o julgamento a ser feito pelo Poder Judiciário acerca da improbidade independe da aprovação ou rejeição das contas pelo órgão de controle interno ou pelo Tribunal ou Conselho de Contas. Acreditamos que o alijamento dos Tribunais de Contas nas ações de improbidade vem acontecendo em decorrência de uma interpretação literal de tal artigo, que vem sendo usado de maneira ampla para justificar a exclusão dessas Cortes de Contas. Esse fato pode ser observado em inúmeras decisões do Superior tribunal de Justiça - STJ, nas quais se firmou o entendimento que a aprovação ou rejeição das contas é irrelevante para o trâmite da Ação Civil Pública de Improbidade?

Em que pese estarmos tratando de decisões emanadas da mais alta corte infraconstitucional do país, entendemos que o entendimento firmado é equivocado e não atende à legislação, à construção de um sistema de controle eficiente e à segurança jurídica,

\footnotetext{
${ }^{8}$ Lei $n^{0}$ 8.429/92: “Art. 21. A aplicação das sanções previstas nesta lei independe:

I - da efetiva ocorrência de dano ao patrimônio público, salvo quanto à pena de ressarcimento

II - da aprovação ou rejeição das contas pelo órgão de controle interno ou pelo Tribunal ou Conselho de Contas."

${ }^{9}$ Temos como exemplo o julgamento do REsp $\mathrm{n}^{0} \quad 1.807 .536$ pelo STJ
} 
especialmente porque, além de interpretar o artigo 21 de forma literal, mistura a questão do julgamento das contas e a questão que envolve as competências originárias dos Tribunais de Contas. Além disso, esse entendimento permite um controle sobreposto e que pode gerar decisões antagônicas e isso aumenta o custo desse mesmo controle, além de ineficiência e insegurança jurídica.

No que concerne a Lei de Improbidade, nosso entendimento é de que o artigo 21 deve ser interpretado como uma autorização para a propositura da Ação de Improbidade no caso da falta de manifestação do órgão de controle interno ou do Tribunal de Contas. Não é razoável, que se permita a análise das contas pelos órgãos de controle externo para depois se estabelecer jurisprudencialmente que essa manifestação é irrelevante para fins da Ação de Improbidade. Então qual é o objetivo do julgamento de contas? Criar mais uma punição apenas? Esses questionamentos surgem especialmente com sistemática que vem sendo adotada pelos Tribunais de Contas, como por exemplo, o de Minas Gerais, onde o gestor público, após a publicação de um Edital de Licitação ou a assinatura de um Contrato Administrativo, precisa inserir no sistema do Tribunal de Contas todos os dados referentes a tais procedimentos, inclusive imagem digitalizada dos originais ${ }^{10}$.

Conforme a sistemática apresentada, temos que os Tribunais de Contas, ao apreciarem as contas para aprová-las ou rejeitá-las, o fazem tendo total conhecimento dos atos administrativos que envolvem suas competências e com presunção juris tantum, tendo em vista que, na qualidade de órgão autônomo e independente, estão investidos de fé pública e seus atos detém presunção de veracidade.

Importante o fato de que, quando há a rejeição de contas ou a aprovação com ressalvas, automaticamente o procedimento é encaminhado para o Ministério Público para eventual propositura de Ação Civil Pública de Improbidade Administrativa, que será lastreada justamente pela análise do Tribunal de Contas. E não menos importante é o fato de que o Ministério Público poderá declinar da impetração de Ação Civil Pública de Improbidade, porém deverá fazê-lo de forma motivada.

10 O Sistema Informatizado de Contas dos Municípios (SICOM) do TCEMG possui um módulo de acompanhamento mensal, que obriga os gestores a informar "dados relativos à execução orçamentária e financeira, alterações orçamentárias, licitações, contratos, notas fiscais e controle de frota" em até 40 dias após o encerramento de cada mês. (Cartilha de Perguntas e Respostas do TCEMG, p. 46-47, disponível em: <https://www.tce.mg.gov.br/img_site/Cartilha_PerguntaseRespostas.pdf> Acesso em 15/12/2020. 
Não existe razão alguma para que o procedimento a ser adotado pelo Ministério Público seja diferente quando as contas forem aprovadas, sendo que, em caso de o Ministério Público optar pelo ajuizamento da Ação Civil de Improbidade Administrativa, deverá igualmente motivar sua decisão e demonstrar nos autos essas razões. Entretanto, tal procedimento não tem sido adotado pelo Ministério Público, que ajuíza a ação desconsiderando o procedimento do Tribunal de Contas, ancorado pelo entendimento do STJ.

Resta a questão prevista em lei, que ocorre quando ainda não houve manifestação do Tribunal de Contas a respeito do julgamento das contas. Nesse caso sim, entendemos que a Ação Civil Pública de Improbidade poderá ser ajuizada à despeito de qualquer procedimento do Tribunal de Contas. Entretanto, caso haja manifestação do Tribunal de Contas durante o curso do processo, tal manifestação deverá integrar a ação.

Entretanto, independentemente de haver ou não apreciação das contas pelos Tribunais de Contas, temos que as Ações de Improbidade normalmente se referem a questões específicas, como por exemplo, questões que envolvam um determinado processo de licitação. O que nos interessa aqui é quando o caso envolvendo esse processo de licitação encontra-se na esfera de competências dos Tribunais de Contas, ou seja, a responsabilidade pelo controle externo pertence aos Tribunais de Contas, que devem se manifestar de ofício ou provocados, na medida em que não o fizerem, através de representação. E nesses casos, entendemos que a participação direta do Tribunais de Contas nas Ações torna-se um imperativo e não só devido à responsabilidade pelo controle externo, mas por ser também o órgão mais bem estruturado para isso.

Nos casos específicos em que os Tribunais de Contas têm a obrigação de fiscalizar e proferir decisões, nossa análise sobre a questão judicial não se altera, muito ao contrário, entendemos que nesses casos a participação dos Tribunais de Contas nas ações judiciais, em especial as de improbidade administrativa que são oriundas dessas obrigações se torna mais imperativa. Entretanto, teremos duas situações que devem ser observadas, quando o Tribunal de Contas já decidiu sobre a questão e quando não houve uma decisão, sendo que nesse último caso o Tribunal de Contas deverá ser chamado a se manifestar sobre a questão específica, mesmo que tardiamente, justificando sua eventual inação, se esta restar comprovada. 
Voltando ao exemplo anterior, de um caso hipotético que envolva um processo de licitação e que será proposta uma Ação Civil Pública de Improbidade Administrativa com base em questões envolvendo as competências dos Tribunais de Contas, impõe a necessidade de se trazer a decisão do órgão de controle externo para a ação. E adotando-se a mesma argumentação já feita, caso seja uma ação a ser proposta pelo Ministério Público, o mesmo deverá utilizar o procedimento feito pelo Tribunal de Contas para embasar a inicial, devendo motivar a decisão de não o fazê-lo.

Importante esclarecer que estamos citando o Ministério Público porque entendemos que se nossa argumentação for adotada pelo órgão, muitas ações judiciais poderão ser evitadas por meio de um procedimento prévio envolvendo o Ministério Público de Contas, representante do parquet junto ao Tribunal de Contas que pode estabelecer uma eficiente interlocução entre os dois órgãos pertencentes ao sistema de controle.

No entanto, compete ao Poder Judiciário exigir essa participação do Tribunal de Contas nas ações judiciais, o que não vem acontecendo, fazendo com que inúmeros processos tramitem simplesmente ignorando a posição das Cortes de Contas.

Compete ao Judiciário deferência ao argumento das capacidades institucionais, especialmente porque, devido a própria natureza do Poder Judiciário, os juízes são generalistas que precisam se preocupar com vários tipos de demandas. Os Tribunais de Contas, por outro lado, são órgãos integrantes do sistema de controle com inegável capacidade institucional para analisar matérias que envolvem suas competências, conforme bem estabeleceu Letícia Ayres Ramos ${ }^{11}$.

Mas tal expertise não vem sendo aproveitada como deveria. Letícia Ayres Ramos (op. cit., p. 165), com o objetivo de tratar da revisibilidade das decisões dos Tribunais de

\footnotetext{
11 "No que diz respeito à forma de atuação dos Tribunais de Contas, alguns aspectos devem ser destacados, pois colaboram com o reconhecimento de uma maior capacidade institucional para proferir decisões no âmbito de suas competências: a) os Tribunais possuem composição multidisciplinar, contando com membros e servidores detentores de conhecimentos jurídicos, contábeis, econômicos e financeiros ou de Administração Pública; b) seus membros possuem garantias constitucionais nos mesmos moldes daquelas dedicadas aos do Poder Judiciário; c) a atuação do Tribunal é capilarizada, ou seja, os procedimentos de diagnósticos das situações são efetuados com a inserção na realidade dos administrados e em todos o território jurisdicional; d) o processo possui grande potencial de contraposição de argumentos, primeiro, em virtude da possibilidade de participação popular nos processos que tramitam na Corte, disposta pelo art. $74, \S 2^{\circ}$, da Constituição e, em segundo, pelo fato de que, a tramitação do processo viabiliza a atuação de vários setores técnicos, além da participação do Ministério Público Especial. Ao Órgão Julgador caberá o ônus de cotejar os argumentos lançados proferindo a decisão adequada para o caso concreto." (RAMOS, op. cit., p. 135-136)
} 
Contas, apresenta em sua Dissertação de Mestrado um excerto de uma decisão do STJ, proferida no REsp $\mathrm{n}^{0} \quad 1.686 .347 / \mathrm{RN}$ que aqui repetimos:

As instâncias administrativas e judiciais são independentes, o que não significa que não ocorra entre elas uma ligação e uma influência, a depender das cores que cercam cada fato. No caso, aqui, a declaração de não demonstração de sua responsabilidade, pelo Poder Judiciário, e, ademais, em ação civil pública por improbidade administrativa, pela sua força, como o último poder a se manifestar sobre o fato, faz com que brote uma substancial influência sobre a execução da multa extraída do julgado do Tribunal de Contas da União, no sentido de retirar-lhe a força executiva. Seria incongruente que o Judiciário aclamasse a não demonstração de sua responsabilidade e, ao mesmo tempo, mantivesse eficaz a multa imposta pelo Tribunal de Contas, que, afinal, se constitui autoridade meramente administrativa. O Judiciário não adentra no mérito da decisão do Tribunal de Contas. O que ocorre é que a não demonstração da responsabilidade da apelante apaga a força da multa aplicada, sem que entre na jogada a conveniência, oportunidade, eficiência ou justiça do ato, fl. 112. Na visão do Tribunal de Contas da União, a apelante merecia uma multa. O Julgador, esmiuçando os atos ligados à construção da obra, não vislumbrou a demonstração da responsabilidade da apelante. A decisão do Judiciário, apesar de não apagar a do Tribunal de Contas, lhe retira a eficácia executiva, porque a última palavra, acerca de qualquer lesão de direito, é do Judiciário.

Na decisão apresentada, em decorrência do não reconhecimento da conduta improba do agente público, o STJ afastou a eficácia da multa aplicada pelo Tribunal de Contas, sem afastar a decisão em si. Em nosso entendimento, essa decisão cria uma espécie de distorção na qual existem duas decisões de mérito antagônicas, uma na esfera administrativa e outra na judicial. Entendemos que a decisão do Tribunal de Contas seria trazida para dentro da Ação Civil Pública de Improbidade Administrativa e a decisão do Poder Judiciário uniformizaria o entendimento, ditando inclusive, as orientações futuras a serem dadas pelos Tribunais de Contas para os agentes públicos.

Acreditamos que a adoção de nosso entendimento possa ser uma realidade, especialmente na jurisprudência do Supremo Tribunal Federal, onde recentemente o Ministro Gilmar Mendes, na qualidade de relator, proferiu voto nos autos do $\mathrm{HC}^{0}$ 107.263/SP, de onde retiramos o seguinte excerto:

Nesse sentido, levando em conta a independência das esferas, o julgamento proferido pelo Tribunal de Contas dando por regular o procedimento administrativo não teria o condão de inviabilizar, primo ictu oculi, a propositura da ação penal pelo Ministério Público. Todavia, o caso para mim é peculiar.

É que o art. 89 da Lei 8.666/93 dispõe como conduta criminosa o ato de "dispensar ou inexigir licitação fora das hipóteses previstas em lei, ou deixar de observar as formalidades pertinentes à dispensa ou à inexigibilidade". Dessarte, indago: Concluindo o Tribunal de Contas pela lisura do procedimento, haveria justa causa para a persecução penal?

Em tese, sim. Contudo, tenho para mim que a aprovação do procedimento pelo Tribunal de Contas vem a exigir do Ministério Público esforço maior no encargo de reunir elementos concretos que atestem a real necessidade de iniciar a persecução penal, mormente indícios de que a Corte de Contas, ao apreciar o feito, 
equivocou-se na conclusão. Entretanto, essa premissa não se deu por aqui, o que, para mim, vem caracterizar constrangimento ilegal e, portanto, flagrante falta de justa causa para prosseguimento da persecução penal.

Como se pode inferir, o voto apresentado adota a argumentação que apresentamos, cabendo a observação de que se trata de Habeas Corpus, ou seja, a matéria foi decidida na esfera criminal, mas não seria a primeira vez que a esfera criminal apontaria o caminho do administrativo, tendo já acontecido anteriormente no próprio âmbito do Supremo Tribunal Federal (GARCIA, 2017).

\section{Conclusão}

O objetivo deste artigo analisar a possibilidade de as decisões e manifestações dos Tribunais de Contas integrarem ações judiciais, em especial a Ação Civil de Improbidade Administrativa.

Nossa argumentação demonstra que a sistemática atual é ineficiente, na medida em que cria competição entre órgão do sistema de controle, gera insegurança jurídica e eleva sobremaneira os custos do controle em si e da estrutura administrativa. Traduzindo o pensamento em uma única palavra, o controle como é ineficiente.

Além dessa ineficiência apontada, a premissa de que o julgamento de contas pelos Tribunais de Contas, ou mesmo suas manifestações são irrelevantes para a propositura da Ação Civil de Improbidade Administrava criou uma cultura, dentro dos próprios Tribunais de Contas, de que sua atuação primeva(??), oriunda de suas competências, vem se tornando menos relevante, na medida em que as questões são levadas ao Poder Judiciário sem sua participação.

Entendemos que isso pode está induzindo a principal Corte de Contas do país, o Tribunal de Contas da União - TCU, a abraçar áreas de atuação que se situam, para parte da doutrina, fora da sua competência constitucional, com o objetivo de continuar relevante. E nesse avanço ultra competência, que atraem severas críticas da doutrina especializada, que por sua vez não desmerecem a importância da atuação dos tribunais de contas, mas que atuam no espectro das atribuições estabelecidas pela Constituição Federal..

É necessário que às Cortes de Contas, no âmbito de suas competências constitucionais, o Poder Judiciário e outros órgãos do complexo de controle da administração 
pública passem a dar maior deferências as decisões colegiadas desse, por serem o órgão de controle constitucionalmente designado para tal.

Ressalta-se que os tribunais de contas possuem um estrutura própria para o exercício dessas competências, pessoal especializado e qualificado e com experiência nos diversos setores que estão sob sua circunscrição de fiscalização. não devendo o Poder Judiciário renunciar a tal expertise.

Contudo, não se pretende insular as decisões dos tribunais de contas do Poder Judiciário, pois estar-se-ia propondo uma inconstitucionalidade (Art. $5^{\circ}, \mathrm{XXXV}$ ). O que se propõe é que se amplie maior deferência aos julgados dos tribunais de contas com, quando a ação versar sobre suas competências constitucionais. Entendemos, que ao não considerar as decisões das cortes de contas, além do desprestígio as funções constitucionais daquelas, o Estado incorre em um custo que não está sendo corretamente utilizado, sem falar na insegurança jurídica daqueles que tem suas contas apreciadas e julgadas por esses órgãos de controle (Art. 71, II). Excluindo-se dessa insegurança os agentes políticos chefes dos executivos, cujas contas sofre julgamento político pela poder legislativo correspondente,

Entendemos que os pontos aqui apresentado levantarão inúmeras outras questões, como por exemplo, qual a forma de participação dos Tribunais de Contas nas ações judiciais? Como Amicus Curiae? Tais questões serão objetos de outros estudos a serem feitos por nós ou por outros acadêmicos interessados em torna nosso sistema de controle mais eficiente.

\section{Referências Bibliográficas}

ARAGÃO, Alexandre Santos de. O Controle da Constitucionalidade pelo Supremo Tribunal Federal à Luz da Teoria dos Poderes Neutrais. Revista de Direito da Procuradoria Geral do Rio de Janeiro. Vol. 57. 2003

BRASIL, TCU, Manual de Auditoria Operacional, 2010.

CRETElla JR, José. Natureza das Decisões do Tribunal de Contas. Revista de Direito Administrativo. FGV. Rio de Janeiro, pp 1-16, out/dez 1986

DI PIETRO, Maria Sylvia Zanella. Coisa Julgada: Aplicabilidade a Decisões do Tribunal de Contas da União. Revista do Tribunal de Contas da União, Brasília, v. 27, n. 70, p. 23-36, 1996 
DOURADO, Rodolfo Maciel. O Controle Externo sobre as Agências Reguladoras de Estado: limites e (im)possibilidades de atuação. Dissertação (Mestrado em Administração). Escola Brasileira de Administração Pública, EBAPE/FGV, Rio de Janeiro, 2011.

GARCIA, Fernando Couto. Controle Judicial das Decisões dos Tribunais de Contas. In: PEREZ, Marcos Augusto e SOUZA, Rodrigo Pagani de. Controle da Administração Pública. Editora Fórum, Capítulo 5, 2017

JACOBY FERNANDES, Jorge Ulisses. Controle das Licitações pelo Tribunal de Contas. Revista de Direito Administrativo. FGV. Rio de Janeiro, pp 95-110. Jan/Mar. 2005

MARQUES NETO, Floriano de Azevedo; PALMA, Juliana Bonacorsi. Diálogos fora de esquadro: o controle das agências reguladoras pelo Tribunal de Contas da União. Revista Brasileira de Estudos Políticos, n. 120, pp. 203-236, jan/jun 2020.

MARQUES NETO, Floriano de Azevedo; PALMA, Juliana Bonacorsi. Os Sete impasses do Controle da Administração Pública no Brasil. In: PEREZ, Marcos Augusto e SOUZA, Rodrigo Pagani de. Controle da Administração Pública. Editora Fórum, Capítulo 1, 2017.

MARQUES NETO, Floriano de Azevedo et al. Reputação institucional e o controle das Agências Reguladoras pelo TCU. Revista de Direito Administrativo, v. 278, n.2, pp. 37-70, mai/ago 2019.

OLIVEIRA, Anderson Márcio de. Intervenção regulatória do TCU: uma avaliação empírica nos processos de concessão da ANTT, ANTAQ e ANAC. Dissertação (Mestrado em Direito da Regulação). Faculdade de Direito, FGV Direito Rio, Rio de Janeiro, 2017.

PEREIRA, Gustavo Leonardo Maia. O TCU e o controle das agências reguladoras de infraestrutura: controlador ou regulador? Dissertação (Mestrado em Direito e Desenvolvimento) - Faculdade de Direito, FGV São Paulo. São Paulo. 2019.

ROSILHO, André Janjácomo. Controle da Administração Pública pelo Tribunal de Contas da União. Tese (Doutorado). Faculdade de Direito, Universidade de São Paulo, São Paulo, 2016.

RAMOS, Letícia Ayres. Controle Judicial das Decisões Condenatórias dos Tribunais de Contas: Uma Proposta de Compatibilização. Dissertação de Mestrado. Universidade Federal do Rio Grande do Sul (UFRGS). 2019 
SABENÇA, Sandro Zachariades. O TCU e o Controle Operacional das Agências Reguladoras: Uma Análise Empírica. Dissertação (Mestrado em Direito da Regulação). Faculdade de Direito, FGV Direito Rio, Rio de Janeiro, 2019.

SUNDFELD, Carlos Ari; CÂMARA, Jacintho Arruda. Controle das contratações públicas pelos Tribunais de Contas. Revista de Direito Administrativo, v. 257, pp. 111-144, mai/ago 2011.

SUNFELD, Carlos Ari; CÂMARA, Jacintho Arruda; MONTEIRO, Vera; ROSILHO, André. O valor das decisões do Tribunal de Contas da União sobre irregularidades em contratos. Revista de Direito GV. São Paulo, V13, N3, p. 866-890. Set-Dez 2017.

WILLEMAN, Marianna Montebello. O desenho institucional dos Tribunais de Contas e Sua vocação para a tutela da accountability democrática: perspectivas em prol do direito à boa administração pública no Brasil. Tese (Doutorado). Departamento de Direito - PUCRio, Rio de Janeiro, 2016. 